\title{
Associations between self-reported fruit and vegetable consumption and home availability of fruit and vegetables among Greek primary-school children
}

\author{
Eleni Koui and Russell Jago* \\ Department of Exercise, Nutrition and Health Sciences, Centre for Sport, Exercise and Health, University of \\ Bristol, Tyndall Avenue, Bristol BS8 ITP, UK
}

Submitted 20 February 2007: Accepted 9 August 2007: First published online 2 January 2008

\begin{abstract}
Objective: To examine whether the self-reported fruit and vegetable consumption of Greek primary-school children is associated with the home availability of fruit and vegetables.

Design: Cross-sectional study.

Setting: Five primary schools in the city of Pyrgos in south-west Greece.

Subjects: One hundred and sixty-seven students in fifth and sixth grades.

Methods: Fruit and vegetable consumption was assessed using an FFQ. Home availability of fruit and vegetables was assessed using a modified version of a US home availability questionnaire. Participant BMI was assessed and parental education obtained by self-report. Hierarchical regression models that took account of the clustering of participants in schools were used to examine the relationship between consumption and availability after controlling for parental education and BMI.

Results: Regression analyses showed that home availability of fruit was a significant predictor of consumption $(\beta=0.524, Z=9 \cdot 77, P<0 \cdot 001)$ in a model that explained $46 \%$ of the overall variance. Home availability of vegetables was a significant predictor of vegetable intake $(\beta=0 \cdot 378, Z=6 \cdot 23, P<0 \cdot 001)$ in a model that explained $29 \%$ of the overall variance.

Conclusion: Home availability of fruit and vegetables was associated with consumption among Greek primary-school children. The association between home availability of fruit and intake was higher than the associations that have been reported in other samples. Results support focusing on the home availability of fruit and vegetables as a potential mediator of consumption that could be manipulated as a means of increasing fruit and vegetable intake among children.
\end{abstract}

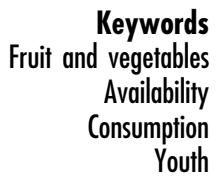

Fruit and vegetables are an important source of micronutrients $^{(1)}$. Fruit and vegetable consumption has been shown to reduce the risk of developing a number of diseases including some forms of cancer $^{(2)}, \mathrm{CHD}^{(3)}$ and obesity $^{(4)}$. Fruit and vegetable consumption during childhood may also reduce the risk of a number of childhood illnesses including respiratory symptoms ${ }^{(5)}$. Unfortunately, despite the well-established benefits of fruit and vegetable consumption, nutritional surveys consistently show that many children and adults do not meet nutritional guidelines ${ }^{(6-8)}$. A recent pan-European survey reported that there was considerable variability between countries in the fruit and vegetable consumption of 11-year-olds, with no consistent geographical variability $^{(9)}$. The considerable variability in the fruit and vegetable consumption of adolescents in neighbouring countries such as Spain ( $40 \mathrm{~g}$ vegetables/d) and Portugal ( $80 \mathrm{~g}$ vegetables/d) suggests a need to identify intake and specific predictors of intake in each country ${ }^{(9)}$.

The mediating variable model indicates that, in order to change youth fruit and vegetable intake, we need to examine the key predictors of fruit and vegetable intake and then manipulate those variables as a means of changing behaviour ${ }^{(10-12)}$. A number of key psychosocial predictors of children's fruit and vegetable consumption, such as attitudes, self-efficacy, preferences and knowledge, have been associated with youth fruit and vegetable consumption $^{(13,14)}$. Interventions that have attempted to manipulate these variables have had limited success ${ }^{(13,15)}$. Home availability of fruits and vegetables is a proximal environmental variable that has been consistently related to fruit and vegetable intake among North American ${ }^{(16)}$ 
and Northern European youth ${ }^{(17-19)}$. Home availability is particularly interesting as it is potentially a relatively easy variable to manipulate and an increase in home availability is likely to result in an increase in consumption ${ }^{(19)}$.

Data from the Pro-Children study has shown that, like consumption, home availability of fruits and vegetables differs across European countries ${ }^{(20)}$. A comparison of the fruit and vegetable availability in ten European countries reported that Greece and Spain had the highest levels of fruit and vegetable availability ${ }^{(21)}$. Interestingly, data from the Pro-Children study indicated that Spanish adolescents reported some of the lowest levels of both fruit and vegetable consumption of the ten countries studied. This would appear to contradict the possible link between consumption and home availability and suggests a need to examine associations in other countries, particularly countries with high levels of availability.

There is very little information about the fruit and vegetable consumption of Greek adolescents, a nation that has previously been identified as a country with a high availability of fruit and vegetables. There is also no information about the association between fruit and vegetable availability and consumption among this group $^{(19)}$. As availability is likely higher in this group ${ }^{(21)}$, examination of whether availability is associated with intake and the strength of any association would provide further information on the possible importance of home availability as a target for intervention. The present study addressed these issues by examining associations between self-reported fruit and vegetable consumption and self-reported fruit and vegetable home availability in a sample of Greek primary-school children.

\section{Methods}

\section{Participants}

Participants were recruited from five randomly selected primary schools in the city of Pyrgos in south-west Greece in summer 2006. After an initial explanation of the study by the lead author, all fifth and sixth grade students in the schools were encouraged to take home to their parents study information packs that included informed consent and assent forms ${ }^{(22)}$. Of the 368 eligible students in the schools, informed consent and assent were obtained from 167 (45\%) students. The study was approved by the University of Bristol Ethics and Research Committee.

\footnotetext{
Measures

Socio-economic status was assessed based on a previous Greek questionnaire ${ }^{(23)}$ that assessed maternal and paternal education according to the length of participation in formal education $(<6$ years, $6-12$ years, $>12$ years). Fruit and vegetable intake was assessed using an FFQ that included two fruit juices, sixteen fruit and
}

sixteen vegetable items. The FFQ was adapted from a previously validated FFQ that was shown to have good reliability and validity among 9-14-year-old US children ${ }^{(24)}$. The questionnaire asks how many servings of each item the respondent has consumed during the last week, with a serving being a single helping of that food. Respondents are told to include fresh, frozen and canned foods. The original items were created on the basis of the most commonly consumed fruit, juices and vegetables reported in the US Continuing Survey of Food Intake by Individuals ${ }^{(24)}$. However, as there is no equivalent data set for Greece, the items were reviewed by the first author and other Greek dietitians and modified according to the foods most likely to be consumed. Deleted foods were $100 \%$ grape juice, $100 \%$ other juice, kiwi, grapefruit, apple sauce, celery, potato salad, corn, broccoli, coleslaw and sweet potatoes, while added foods were cherries, nectarines, aubergines, courgettes, potatoes, pulses (lentils/ beans), cucumber and radishes. The FFQ asks about the previous seven days and asks respondents to report consumption for each item in seven categories: none, 1 serving, 2-3 servings, 4-6 servings, 7 servings, 8-14 servings, 15 or more servings in the past week. Prior to completion the first author provided the students with instructions and was available to answer any questions.

Home availability of fruits and vegetables was reported by the student using a modified version of the Cullen questionnaire $^{(16)}$. The Cullen questionnaire has been validated against self-inventories and has been used widely ${ }^{(25)}$. The questionnaire asks, using a yes/no response, whether fruits and vegetables on the given list were available in the student's home during the past week. The questionnaire was modified to include the foods on the revised Greek FFQ. All questionnaires were translated into Greek and the translation checked for accuracy by another bilingual Greek dietitian. All measures were completed in a school classroom with the lead author available to answer any participant's questions.

\section{Anthropometric assessments}

Body weight was assessed to the nearest $0 \cdot 1 \mathrm{~kg}$ according to a standard protocol using a digital scale ${ }^{(26)}$. Height was assessed to $0.5 \mathrm{~cm}$ using a standard protocol and a measuring tape ${ }^{(26)}$. All measurements were taken by a registered dietitian and BMI was calculated $\left(\mathrm{kg} / \mathrm{m}^{2}\right)$. For descriptive purposes, BMI was also used to classify participants as normal weight, overweight and obese according to the cut-off points for childhood obesity of the International Obesity Task Force ${ }^{(27)}$.

\section{Data reduction}

Data from the FFQ were reduced using the mean value of the category (thus 2-3 servings was coded as $2 \cdot 5$, 4-6 was coded as 5, 8-14 was coded as 11,15 or more was coded 
as 15). The total weekly servings were then divided by seven to obtain the daily consumption of each item. As evidence suggests that youth view fruit and juices separately (e.g. negative peer influences for eating vegetables, but not fruits or juices) ${ }^{(28)}$, fruits and juices were combined and summed with separate analyses performed for summed vegetable (excluding potatoes) consumption. The number of fruits and vegetables available in the home was summed for each participant.

\section{Statistical analysis}

Descriptive statistics, means, standard deviations and percentages, were calculated for all variables. Cronbach's alpha was run to assess the internal consistency of the intake and availability measures in this sample. Bivariate correlations were performed among fruit and juice and vegetable availability and intake, age and BMI. Participant-reported fruit consumption and fruit availability were then dichotomised as low (less than the mean) or high (greater than or equal to the mean). A Pearson $\chi^{2}$ test was then used to test for differences in these groupings. This process was then repeated separately for vegetable consumption and availability.

Hierarchical linear regression models that took account of the clustering of participants in schools were calculated to examine the extent to which availability predicted consumption. Models were run using the xtreg command in the STATA statistical software package version 9.0 (StataCorp, College Station, TX, USA) with intake (either vegetable or fruit and juice) as the dependent variable and availability (either vegetable or fruit and juice) as the independent variable while also controlling for gender (male as the reference group). School was included as a random effect. As youth fruit and vegetable consumption has previously been reported to vary by the respondent's adiposity, BMI was also included in the models ${ }^{(29,30)}$. Father's education was also included in the models, but as father's and mother's education were significantly correlated $(r=0.633, P<0.001)$, mother's education was excluded. The within-school $R^{2}$, the between-school $R^{2}$ and the overall $R^{2}$, which is analogous to the $R^{2}$ obtained from non-nested models, were also produced.

\section{Results}

Descriptive statistics for the 167 students who took part in this study are shown in Table 1 . The sample was $52 \%$ female and $37 \%$ of the participants were overweight with an additional $11 \%$ obese. Parental education data were obtained for only 118 of the 167 participants. The mean daily fruit and juice consumption was $3 \cdot 1$ servings, with $2 \cdot 7$ servings of vegetables (excluding potatoes). The mean number of fruits available in the home was $7 \cdot 0$ and $8 \cdot 1$ for vegetables. Cronbach's $\alpha$ for fruit intake was $0 \cdot 808$
Table 1 Descriptive statistics for participant characteristics, fruit and vegetable intake, and fruit and vegetable availability: Greek primary-school children

\begin{tabular}{lrrr}
\hline Variable & $n$ & $\%$ \\
\hline Gender & & & \\
$\quad$ Male & 81 & $48 \cdot 5$ & \\
$\quad$ Female & 86 & $51 \cdot 5$ & \\
Father's education & & & \\
$\quad<6$ years & 22 & $13 \cdot 2$ & \\
$6-12$ years & 53 & $30 \cdot 5$ & \\
$>12$ years & 43 & $25 \cdot 7$ & \\
$\quad$ Missing & 49 & $30 \cdot 5$ & \\
Mother's education & & & \\
$\quad<6$ years & 9 & $5 \cdot 4$ & \\
$6-12$ years & 59 & $35 \cdot 3$ & \\
$>12$ years & 50 & $29 \cdot 9$ & \\
$\quad$ Missing & 49 & $29 \cdot 3$ & \\
Obesity & & & \\
$\quad$ Overweight & 61 & $36 \cdot 5$ & \\
Obese & 18 & $10 \cdot 8$ & \\
& & & \\
$\quad$ & $n$ & Mean & SD \\
\cline { 2 - 4 } Age (years) & 167 & $11 \cdot 38$ & $0 \cdot 63$ \\
BMl (kg/m ${ }^{2}$ ) & 167 & $20 \cdot 67$ & $3 \cdot 43$ \\
Fruit and juice (servings/d) & 167 & $3 \cdot 14$ & $1 \cdot 89$ \\
Vegetables (excl. potatoes) (servings/d) & 167 & $2 \cdot 74$ & $1 \cdot 70$ \\
Fruit availability & 167 & $7 \cdot 02$ & $2 \cdot 61$ \\
Vegetable availability (excl. potatoes) & 167 & $8 \cdot 14$ & $2 \cdot 29$ \\
\hline
\end{tabular}

and 0.848 for vegetable intake (excluding potatoes), indicating high internal consistency for these measures in this sample. Cronbach's $\alpha$ for fruit availability was 0.632 and 0.596 for vegetable availability (excluding potatoes), suggesting reasonable internal consistency.

Pearson correlations between intake, availability and demographic variables are presented in Table 2. Fruit availability was significantly correlated with vegetable availability $(r=0.589, P<0.001)$, fruit intake $(r=0.707$, $P<0 \cdot 001)$ and vegetable intake $(r=0.459, P<0 \cdot 001)$. Vegetable availability was significantly correlated with fruit intake $(r=0.472, P<0.001)$ and vegetable consumption $(r=0.510, P<0 \cdot 001)$. Fruit intake was significantly correlated with vegetable intake $(r=0 \cdot 687$, $P<0 \cdot 001)$ while vegetable intake was significantly associated with age $(r=0 \cdot 155, P=0 \cdot 046)$.

The cross-tabulations showing the association between self-reported fruit and vegetable availability and intake are presented in Table 3. Participants who reported a low consumption of vegetables were likely to reside in homes with limited vegetable availability. The same pattern was also evident for fruit.

The regression model predicting vegetable consumption (excluding potatoes) for the 118 participants with complete data for all variables is shown in Table 4. The home availability of vegetables was a significant predictor ( $Z=6 \cdot 23, \quad P<0 \cdot 001)$ of consumption, while the consumption in the highest maternal education group was significantly lower $(Z=-2 \cdot 02, P=0 \cdot 043)$ than in the lowest education group. The model accounted for $29 \%$ of 
Table 2 Correlations among diet, availability and demographic variables: Greek primary-school children

\begin{tabular}{|c|c|c|c|c|c|c|}
\hline & Fruit availability & Vegetable availability & Fruit intake & Vegetable intake & Age & BMI \\
\hline Vegetable availability & $0.589^{\star \star}$ & & & & & \\
\hline Fruit intake & $0 \cdot 707^{\star \star}$ & $0 \cdot 472^{\star \star}$ & & & & \\
\hline Vegetable intake (excl. potatoes) & $0.459^{\star *}$ & $0.510^{\star *}$ & $0.687^{\star *}$ & & & \\
\hline Age & $0 \cdot 112$ & 0.082 & 0.055 & $0 \cdot 155^{\star}$ & & \\
\hline $\mathrm{BMI}$ & -0.027 & -0.010 & -0.024 & -0.063 & 0.085 & \\
\hline Gender & -0.026 & 0.090 & 0.039 & -0.033 & $-0 \cdot 130$ & $0 \cdot 113$ \\
\hline Father's education & 0.056 & $0 \cdot 165$ & 0.079 & -0.040 & -0.073 & -0.044 \\
\hline Mother's education & 0.028 & $0 \cdot 128$ & -0.019 & $-0 \cdot 141$ & $-0 \cdot 110$ & 0.040 \\
\hline
\end{tabular}

Correlation was statistically significant: ${ }^{*} P<0.05 ;{ }^{*} P<0.001$.

Table 3 Cross-tabulation of high and low fruit and vegetable consumption and availability: Greek primary-school children

\begin{tabular}{|c|c|c|c|c|c|}
\hline \multicolumn{3}{|c|}{ Vegetables } & \multicolumn{3}{|c|}{ Fruit } \\
\hline \multirow[b]{2}{*}{ Intake } & \multicolumn{2}{|c|}{ Availability } & \multirow[b]{2}{*}{ Intake } & \multicolumn{2}{|c|}{ Availability } \\
\hline & Low & High & & Low & High \\
\hline Low & 86 & 14 & Low & 87 & 7 \\
\hline $\mathrm{High}_{2}$ & 40 & 27 & High & 39 & 34 \\
\hline \multicolumn{3}{|c|}{$\chi^{2}=14.980, P<0.001$} & \multicolumn{3}{|c|}{$\chi^{2}=33.963, P<0.001$} \\
\hline
\end{tabular}

the variance within schools and $28 \%$ of the overall variance but only $5 \%$ of the variance between schools.

The regression model predicting fruit consumption for the 118 participants with complete data for all variables is shown in Table 5. Fruit availability was the only significant predictor of consumption $(Z=9 \cdot 77, P<0 \cdot 001)$ in a model that accounted for $47 \%$ of the variance within schools, $10 \%$ of the variance between schools and $46 \%$ of the overall variance.

\section{Discussion}

The present study has shown that fruit and vegetable availability are significantly associated with consumption among Greek primary-school students. Moreover, we have also shown that these associations were maintained after accounting for age, gender, BMI and father's education in models that control for the clustering of participants within schools. Interestingly, cross-tabulations showed that participants with low consumption were likely to live in homes with low availability of fruit and vegetables. Although respondents with high consumption tended to be approximately evenly split among those residing in low and high availability households, this finding suggests that home availability is an important influence on Greek children's fruit and vegetable consumption. Moreover, home availability might be a particularly important influence on children with low consumption and could be a key intervention target for this group.

Our results are similar those reported previously among US and Northern European adolescents. For example, among Norwegian sixth and eighth grade students a fruit and vegetable accessibility scale that included availability items was correlated $(r=0 \cdot 44)$ with fruit and vegetable intake obtained from an $\mathrm{FFQ}^{(17)}$. Similarly, among fourth to sixth grade students in Houston, Texas the availability of fruits and vegetables was correlated $(r=0 \cdot 21)$ with intake obtained via a food record ${ }^{(16)}$.

The associations found in the present study are stronger than those reported earlier, with a correlation of 0.7 for the association between fruit intake and availability and 0.5 for the association between vegetable availability and intake. These associations were maintained in the regression models, which accounted for $28 \%$ of the overall variance in the vegetable model and $46 \%$ of the variance in the fruit model. The variance in fruit accounted for by these models is considerably greater than the $30 \%$ that has traditionally been reported as the maximum amount of variance in fruit and vegetable consumption among children after accounting for demographics, availability and other psychosocial variables such as self-efficacy ${ }^{(17,31-33)}$. The variance accounted for in the vegetable model is less than the 39\% that was recently reported among Icelandic youth with low vegetable consumption (less than 1 serving/d) ${ }^{(34)}$. The associations between fruit availability and intake are likely a by-product of the Greek lifestyle whereby the home is the main place where children have most of their meals, including access to fruits and vegetables. Less fruit and vegetable consumption outside the home may aid the formation of desirable dietary patterns without distractions from other environments. The implication of this finding is that Greek children who live in homes that have high availability of fruits and vegetables are likely to consume more of these foods. Promoting home availability is therefore likely to be an important intervention mechanism.

Our finding that high availability of fruit and vegetables is associated with high consumption appears consistent with US literature in which lower levels of consumption have been reported and consumption has been linked to availability. At first glance this finding would appear to suggest that a consistent relationship exists between these variables. However, data from the Pro-Children study have shown that 11-year-olds' fruit and vegetable 
Table 4 Regression model predicting mean daily vegetable consumption: Greek primary-school children

\begin{tabular}{|c|c|c|c|c|c|}
\hline Independent variable & $\beta$ & $\mathrm{SE}$ & $95 \% \mathrm{Cl}$ & $Z$ & $P$ \\
\hline Vegetable availability & 0.378 & 0.06 & $0.259,0.498$ & $6 \cdot 23$ & $<0.001$ \\
\hline $\mathrm{BMl}$ & 0.010 & 0.04 & $-0.068,0.089$ & 0.25 & 0.799 \\
\hline Gender (ref. Male) & -0.397 & $0 \cdot 27$ & $-0.915,0.120$ & $-1 \cdot 50$ & 0.133 \\
\hline \multicolumn{6}{|c|}{ Mothers education (ref. $<6$ years) } \\
\hline $6-12$ years & $-0 \cdot 450$ & 0.51 & $-1 \cdot 456,0.558$ & -0.88 & 0.381 \\
\hline$>12$ years & $-1 \cdot 052$ & 0.52 & $-2 \cdot 072,-0.032$ & $-2 \cdot 02$ & 0.043 \\
\hline Within-school $R^{2}=0.293$ & \multicolumn{3}{|c|}{ Between-group $R^{2}=0.054$} & \multicolumn{2}{|c|}{ Overall $R^{2}=0.282$} \\
\hline
\end{tabular}

Table 5 Regression model predicting mean daily fruit and juice consumption: Greek primary-school children

\begin{tabular}{|c|c|c|c|c|c|}
\hline Independent variable & $\beta$ & SE & $95 \% \mathrm{Cl}$ & $Z$ & $P$ \\
\hline Fruit availability & 0.524 & 0.05 & $0.420,0.630$ & $9 \cdot 77$ & $<0.001$ \\
\hline BMI & 0.017 & 0.04 & $-0.062,0.010$ & $0 \cdot 42$ & 0.676 \\
\hline Gender (ref. Male) & $0 \cdot 321$ & 0.27 & $-0.201,0.843$ & $1 \cdot 20$ & $0 \cdot 228$ \\
\hline \multicolumn{6}{|c|}{ Mothers education (ref. $<6$ years) } \\
\hline $\begin{array}{l}6-12 \text { years } \\
>12 \text { years }\end{array}$ & $\begin{array}{l}-0.601 \\
-0.526\end{array}$ & $\begin{array}{l}0.52 \\
0.52\end{array}$ & $\begin{array}{l}-1 \cdot 604,0 \cdot 401 \\
-1 \cdot 536,0.484\end{array}$ & $\begin{array}{l}-1 \cdot 18 \\
-1 \cdot 02\end{array}$ & $\begin{array}{l}0.239 \\
0.308\end{array}$ \\
\hline Within-school $R^{2}=0.479$ & \multicolumn{3}{|c|}{ Between-group $R^{2}=0.106$} & \multicolumn{2}{|c|}{ Overall $R^{2}=0.461$} \\
\hline
\end{tabular}

consumption in Spain is lower than that of similar aged children in countries such as Norway and Sweden that have lower levels of availability ${ }^{(9,21)}$. While these inconsistencies could be a product of the methods used to assess both availability and intake, it seems likely that national, culturally specific factors are also important. This would imply that we need to understand the association between availability and intake in different countries, and what the cultural influences on this association might be. Potentially important factors could be family meal times and parenting style, as well as more general social trends within the country ${ }^{(35,36)}$. Once associations and influences have been established more work is needed to ascertain if the cultural influences from one country can be translated to another as a means of increasing consumption.

There was no significant association between fruit consumption and BMI or between vegetable consumption and BMI. This is contrary to previous studies in the $\mathrm{USA}^{(29)}$ and Spain ${ }^{(30)}$, which found that increased consumption of fruit and vegetables was associated with a lower BMI. The lack of an association of either food group with BMI might suggest that associations between BMI and fruit and vegetable consumption differ by country. Understanding the possible reasons for these country differences could provide insights into the possible utility of increasing fruit and vegetable consumption as a means of preventing childhood obesity. More work is therefore needed to tease out the possible causes of these different associations.

Consumption of vegetables differed according to father's education level, with participants who lived in higher educated households consuming fewer vegetables than the least educated group. Our finding is therefore different from the associations that have previously been reported in studies from the $\mathrm{UK}^{(7)}$ and The Netherlands ${ }^{(37)}$, where vegetable consumption was found to be higher among more affluent socio-economic groups. The difference between these studies suggests that there is likely something unique about the fruit and vegetable consumption of Greek adolescents. More work is therefore needed to elucidate the dietary patterns of this group, associations with home availability and the reasons for these associations. Such information could then be used to develop more effective intervention approaches.

\section{Strengths and limitations}

The present study enhances previous work by reporting the association between fruit and vegetable consumption and home availability of fruits and vegetables among children who reside in a country where fruits and vegetables are routinely available in large quantities within the home. Its data therefore provide information that supports the promotion of home availability of fruits and vegetables in populations that currently have low levels of home availability.

The study is limited by the relatively small sample drawn from a single city in south-west Greece and the absence of parental educational data for forty-nine participants. The consent rate achieved in the present work was considerably lower than the rates reported in similar studies such as the multi-national Pro-Children study $^{(9)}$. The low consent rate limits our ability to generalise our findings beyond our sample. Furthermore, although we used a previously validated FFQ the scale was modified for the local population and we do not have 
test-retest data in this population. FFQ are reliant on the participants' perception of frequency and portion size ${ }^{(38)}$ and the tool we used assessed consumption of multiple, individual fruits and vegetables which may lead to an overestimation of intake ${ }^{(39)}$.

It is also important to acknowledge that we assessed the potential importance of only one variable on the fruit and vegetable consumption of Greek children. As a number of psychosocial variables such as self-efficacy and taste preferences ${ }^{(20,33)}$ have been associated with consumption, it could be that these variables accounted for part of the variance in the models and therefore the importance of availability was inflated in our analyses. However, the correlations between intake variables and home availability are higher than those reported in many other studies ${ }^{(19)}$, suggesting that home availability is a stronger predictor of intake among Greek children than in many other groups. More work is therefore needed to determine what the causes of such differences might be.

\section{Conclusions}

The data presented herein indicate that home availability of fruit and vegetables is associated with intake among Greek children. Importantly, the data indicate that the association between fruit intake and consumption is substantially higher than the associations reported among Northern European and American populations. We have also shown that participants who resided in homes that did not have many fruits and vegetables were likely to consume less fruit and vegetables than their counterparts who had a high home availability of fruits and vegetables. These findings therefore provide support for an association between availability and intake, and suggest that promoting home availability of fruit and vegetables could be an important means of increasing consumption.

\section{Acknowledgements}

The data reported in the present article were collected as part of the first author's MSc dissertation that was supervised by R.J. Both authors participated in the conception and writing of the paper. R.J. performed the analysis. We have no conflicts of interest.

\section{References}

1. Woodside JV, McCall D, McGartland C \& Young IS (2005) Micronutrients: dietary intake $v$. supplement use. Proc Nutr Soc 64, 543-553.

2. Block G, Patterson B \& Subar A (1992) Fruit, vegetables, and cancer prevention: a review of the epidemiological evidence. Nutr Cancer 18, 1-29.
3. Joshipura KJ, Hu FB, Manson JE et al. (2001) The effect of fruit and vegetable intake on risk for coronary heart disease. Ann Intern Med 134, 1106-1114.

4. Epstein LH, Gordy CC, Raynor HA, Beddome M, Kilanowski CK \& Paluch R (2001) Increasing fruit and vegetable intake and decreasing fat and sugar intake in families at risk for childhood obesity. Obes Res 9, 171-178.

5. Antova T, Pattenden S, Nikiforov B et al. (2003) Nutrition and respiratory health in children in six Central and Eastern European countries. Thorax 58, 231-236.

6. Brady LM, Lindquist CH, Herd SL \& Goran MI (2002) Comparison of children's dietary intake patterns with US dietary guidelines. Br J Nutr 84, 361-367.

7. Wardle J, Jarvis MJ, Steggles N, Sutton S, Williamson S, Farrimond H, Cartwright M \& Simon AE (2003) Socioeconomic disparities in cancer-risk behaviors in adolescence: baseline results from the Health and Behaviour in Teenagers Study (HABITS). Prev Med 36, 721-730.

8. Hoare J, Henderson L, Bates CJ, Prentice A, Birch M, Swan G \& Farron M (2004) The National Diet and Nutrition Survey: Adults Aged 19 to 64 Years - Summary Report. London: Office for National Statistics.

9. Yngve A, Wolf A, Poortvliet E et al. (2005) Fruit and vegetable intake in a sample of 11-year-old children in 9 European countries: The Pro Children Cross-sectional Survey. Ann Nutr Metab 49, 236-245.

10. Baranowski T, Anderson C \& Carmack C (1998) Mediating variable framework in physical activity interventions. How are we doing? How might we do better? Am J Prev Med 15, 266-297.

11. Baranowski T \& Jago R (2005) Understanding mechanisms of change in children's physical activity programs. Exerc Sport Sci Rev 33, 163-168.

12. Baranowski T, Klesges LM, Cullen KW \& Himes JH (2004) Measurement of outcomes, mediators, and moderators in behavioral obesity prevention research. Prev Med 38, Suppl., S1-S13.

13. Blanchette L \& Brug J (2005) Determinants of fruit and vegetable consumption among 6-12-year-old children and effective interventions to increase consumption. J Hum Nutr Diet 18, 431-443.

14. Steptoe A, Perkins-Porras L, McKay C, Rink E, Hilton S \& Cappuccio FP (2003) Psychological factors associated with fruit and vegetable intake and with biomarkers in adults from a low-income neighbourhood. Health Psychol 22, 148-155.

15. Knai C, Pomerleau J, Lock K \& McKee M (2006) Getting children to eat more fruit and vegetables: a systematic review. Prev Med 42, 85-95.

16. Cullen KW, Baranowski T, Owens E, Marsh T, Rittenberry L \& de Moor C (2003) Availability, accessibility, and preferences for fruit, $100 \%$ fruit juice, and vegetables influence children's dietary behavior. Health Educ Behav 30, 615-626.

17. Bere E \& Klepp KI (2004) Correlates of fruit and vegetable intake among Norwegian schoolchildren: parental and self-reports. Public Health Nutr 7, 991-998.

18. Bere E \& Klepp KI (2005) Changes in accessibility and preferences predict children's future fruit and vegetable intake. Int J Behav Nutr Phys Act 2, 15.

19. Jago R, Baranowski T \& Baranowski J (2007) Fruit and vegetable availability: a micro environmental mediating variable? Public Health Nutr 10, 1508-1514.

20. Sandvik C, De Bourdeaudhuij I, Due P et al. (2005) Personal, social and environmental factors regarding fruit and vegetable intake among schoolchildren in nine European countries. Ann Nutr Metab 49, 255-266.

21. Naska A, Vasdekis VG, Trichopoulou A et al. (2000) Fruit and vegetable availability among ten European countries: how does it compare with the 'five-a-day' 
recommendation? DAFNE I and II projects of the European Commission. BrJ Nutr 84, 549-556.

22. Jago R \& Bailey R (2001) Ethics and paediatric exercise science: issues and making a submission to a local ethics and research committee. J Sport Sci 19, 527-535.

23. Krassas GE, Tzotzas T, Tsametis C \& Konstantinidis $T$ (2001) Determinants of body mass index in Greek children and adolescents. J Pediatr Endocrinol Metab 14, Suppl. 5, $1327-1333$

24. Cullen KW, Baranowski T, Baranowski J, Hebert D \& de Moor C (1999) Pilot study of the validity and reliability of brief fruit, juice and vegetable screeners among inner city African-American boys and 17 to 20 year old adults. $J$ Am Coll Nutr 18, 442-450.

25. Cullen KW, Klesges LM, Sherwood NE, Baranowski T, Beech B, Pratt C, Zhou A \& Rochon J (2004) Measurement characteristics of diet-related psychosocial questionnaires among African-American parents and their 8- to 10-yearold daughters: results from the Girls' health Enrichment Multi-site Studies. Prev Med 38, Suppl., S34-S42.

26. Lohman TG, Roche AF \& Martorell R (1988) Anthropometric Standardization Reference Manual. Champaign, IL: Human Kinetics.

27. Cole TJ, Bellizzi MC, Flegal KM \& Dietz WH (2000) Establishing a standard definition for child overweight and obesity worldwide: international survey. BMJ $\mathbf{3 2 0}$, 1240-1243.

28. Cullen KW, Baranowski T, Baranowski J, Warnecke C, de Moor C, Nwachokor A, Hajek RA \& Jones LA (1998) '5 A Day' achievement badge for urban boy scouts: formative evaluation results. J Cancer Educ 13, 162-168.

29. Cullen KW, Baranowski T, Klesges LM, Watson K, Sherwood NE, Story M, Zakeri I, Leachman-Slawson D \& Pratt C (2004) Anthropometric, parental, and psychosocial correlates of dietary intake of African-American girls. Obes Res 12 Suppl., 20S-31S.

30. Perez-Rodrigo C, Aranceta Bartrina J, Serra Majem L, Moreno B \& Delgado Rubio A (2006) Epidemiology of obesity in Spain. Dietary guidelines and strategies for prevention. Int J Vitam Nutr Res 76, 163-171.

31. Wind M, De Bourdeaudhuij I, te Velde SJ, Sandvik C, Due P, Klepp KI \& Brug J (2006) Correlates of fruit and vegetable consumption among 11-year-old BelgianFlemish and Dutch schoolchildren. J Nutr Educ Behav 38, 211-221.

32. Martens MK, van Assema P \& Brug J (2005) Why do adolescents eat what they eat? Personal and social environmental predictors of fruit, snack and breakfast consumption among 12-14 year old Dutch adolescents. Public Health Nutr 8, 1258-1265.

33. Baranowski T, Cullen KW \& Baranowski J (1999) Psychosocial correlates of dietary intake: advancing dietary intervention. Annu Rev Nutr 19, 17-40.

34. Kristjansdottir AG, Thorsdottir I, De Bourdeaudhuij I, Due P, Wind M \& Klepp KI (2006) Determinants of fruit and vegetable intake among 11 -year-old schoolchildren in a country of traditionally low fruit and vegetable consumption. Int J Behav Nutr Phys Act 3, 41.

35. Kremers SPJ, Brug J, de Vries H \& Engels RCME (2003) Parenting style and adolescent fruit consumption. Appetite 41, 43-50.

36. Nicklas TA, Baranowski T, Baranowski JC, Cullen K, Rittenberry L \& Olvera N (2001) Family and child-care provider influences on preschool children's fruit, juice, and vegetable consumption. Nutr Rev 59, 224-235.

37. Hulshof KF, Brussaard JH, Kruizinga AG, Telman J \& Lowik MR (2003) Socio-economic status, dietary intake and 10 y trends: the Dutch National Food Consumption Survey. Eur J Clin Nutr 57, 128-137.

38. Willett WC (1998) Nutritional Epidemiology. New York: Oxford University Press.

39. Krebs-Smith SM, Heimendinger J, Subar AF, Patterson BH \& Pivonka E (1995) Using food frequency questionnaires to estimate fruit and vegetable intake: association between the number of questions and total intake. J Nutr Educ 27, $80-85$. 